\title{
Characterization of Resistance Mechanisms to Erysiphe pisi in Medicago truncatula
}

\author{
Elena Prats, María J. Llamas, and Diego Rubiales
}

CSIC, Institute of Sustainable Agriculture, Apdo. 4084, E-14080 Córdoba, Spain.

Accepted for publication 17 March 2007.

\begin{abstract}
Prats, E., Llamas, M. J., and Rubiales, D. 2007. Characterization of resistance mechanisms to Erysiphe pisi in Medicago truncatula. Phytopathology 97:1049-1053.

In this work, we studied the resistance of 277 Medicago truncatula accessions against powdery mildew and further characterized the defense mechanisms of resistant plants. Ten resistant accessions were selected according to macroscopic assessment. Histological studies showed a range of defense mechanisms, acting alone or combined, that impeded

by the fungus but then hypersensitive response (HR) leading to cell death hampered fungal development. In some cases, cell death was very fast and no haustorium could be observed in epidermal cells, whereas in others, haustoria and secondary hyphae indicated a slow HR. Finally, in some accessions in which no HR was observed, colony growth was restricted through posthaustorial defense mechanisms. Characterization of defense mechanisms will be useful for further cellular and molecular studies to unravel the bases of resistance in this species in particular and in legume-powdery mildew interaction in general.
\end{abstract} fungal development at different stages. Some accessions allowed a reduced spore germination frequency compared with that of the susceptible control. In others, the fungus was arrested at penetration stage due to papilla formation. Epidermal cells of several accessions were penetrated
Additional keywords: barrel medic, posthaustorial resistance, prepenetration resistance.
Annual medics (Medicago species) are widely used in low rainfall areas, often replacing clovers, as a high-quality winter feed supplement, for basic pasture and for soil improvement $(16,28)$. In addition, barrel medic ( $M$. truncatula $\mathrm{L}$.) has emerged as an important model plant species for structural and functional genomics (7). Key attributes of $M$. truncatula include its small diploid genome, its self-fertile nature, its prolific seed production, its rapid generation time, and the ease with which it can be transformed (2,7). M. truncatula is closely related to the cultivated tetraploid alfalfa (M. sativa L.) and to other legumes such as pea, chickpea, faba bean, and lentil. This close phylogenic relationship increases the value of $M$. truncatula as a resource for understanding the important agronomic traits of grain and forage legumes.

Disease resistance is a desirable trait in any crop and it is so in $M$. truncatula. Screening for new sources of resistance is a valuable tool that ultimately may lead to the incorporation of the resistance traits into a cultivated genotype. In addition, much of the research on plant disease responses has been conducted with Arabidopsis as a model. Substantial similarities between the defense responses of Arabidopsis and legumes exist; however, there are also significant differences (1). Thus, it is necessary to increase our understanding on specific aspects of the defense response in legumes in order to solve major constraints of these crops. In this aspect, the powerful "omics" tools implemented for $M$. truncatula make this species highly suitable for these studies (8). Nevertheless, for a better understanding of the molecular basis underlying resistance, it is crucial to have genotypes in which different resistance mechanisms are well-known and characterized.

Powdery mildews are biotrophic pathogens that seriously constrain crop production in many temperate regions; especially Erysiphe spp. cause considerable losses in legumes (20,23). De-

Corresponding author: E. Prats; E-mail address: bb2prpee@uco.es

doi:10.1094/PHYTO-97-9-1049

(c) 2007 The American Phytopathological Society spite this, most studies on resistance have been carried out in the cereal-powdery mildew interaction $(11,12,15,29)$. Establishment of functional biotrophy by powdery mildew can broadly be considered a two-stage process (27). The first depends upon the appressorial penetration peg penetrating the plant cuticle-epidermal cell wall barrier and then breaching the papilla that is deposited as a response to attempted penetration $(25,29)$. Failure of attempted penetration, due to plant resistance associated with papilla formation and/or cell wall strengthening, obviously prevents colony establishment. The second stage requires that upon entering the plant cell, the fungal penetration peg differentiates a haustorium without killing its host cell and, from it, absorbs nutrients to support colony growth $(25,29)$. Death of the invaded epidermal cell after penetration of the host wall/papilla barrier arrests haustorium development and again stops colony development. In some cases, after the fungus establishes a functional haustorium, posthaustorial resistance may delay growth of secondary hyphae, maturation of secondary appressoria, and therefore sporulation of the colony (18).

In the present work, we aimed to find new sources of resistance to powdery mildew (Erysiphe pisi Syd., syn. E. polygoni DC.) in $M$. truncatula for use in barrel medic breeding programs. In addition, we sought to characterize the resistance mechanisms acting in the resistant genotypes as a starting point for cellular and molecular studies that will further reveal the basis of resistance.

\section{MATERIALS AND METHODS}

Plant and pathogen materials. Seed of the 277 accessions studied was provided by the U.S. Department of Agriculture. Seeds were germinated in petri dishes with moistened filter papers in dark for $48 \mathrm{~h}$ in a growth chamber at $65 \%$ relative humidity and $20^{\circ} \mathrm{C}$. Then, seedlings were sowed in $125-\mathrm{ml}$ pots filled with peat/sand $(3: 1)$ and returned to the chamber. Plants were grown at $20^{\circ} \mathrm{C}, 65 \%$ relative humidity, and under $12 \mathrm{~h}$ dark/ $12 \mathrm{~h}$ light with $250 \mu \mathrm{mol} \mathrm{m} \mathrm{m}^{-2} \mathrm{~s}^{-1}$ photon flux density supplied by 
high-output white fluorescent tubes for approximately 4 weeks until plants had four expanded leaves.

Plants were inoculated with E. pisi f. sp. medicaginis isolate CO05, collected on M. truncatula plants in Córdoba (Spain). The isolate was maintained on susceptible M. truncatula cv. Parabinga. One day before inoculum was required, heavily infected plants were shaken to remove ageing conidia and ensure a supply of vigorous young spores.

Macroscopic assessment of symptom development following inoculation with $\boldsymbol{E}$. pisi f. sp. medicaginis. In a first experiment, the whole collection was studied for disease severity to rule out those plants showing susceptibility from the histological studies.

For this screening, three plants of each accession (Table 1) were assessed. When the fourth trifoliate leaf was fully expanded (25 days), plants were inoculated with $E$. pisi f. sp. medicaginis using a settling tower (15) to give about 30 conidia $\mathrm{mm}^{-2}$. Plants were maintained in the above mentioned growth chamber for 8 days before assessment of the percentage of area covered by powdery mildew on inoculated leaf. Susceptible cv. Parabinga was used as control. Plants showing less than $40 \%$ of the leaves covered by powdery mildew were taken for further histological studies.

Microscope observations of $\boldsymbol{E}$. pisi f. sp. medicaginis development and epidermal cell responses to attack on secondformed leaves. Inoculation, fixation, and clearing. Ten plants of each accession that had previously shown less than $40 \%$ mycelium covering the leaf were grown in randomized blocks for 25 days, at which time the fourth-formed leaf was fully expanded. Four plants from these 10 were selected as being at the same developmental stage, and the second-formed leaves of these plants were excised. These leaves were placed (adaxial surface up) beneath the settling tower, with the petiole covered by moistened tissue paper. Then, they were inoculated with 30 conidia $\mathrm{mm}^{-2}$ and immediately returned to a glass with water inside the growth cabinet. At $48 \mathrm{~h}$ after inoculation, four leaves of the selected accessions were fixed on pads moistened with $3: 1$, ethanol/glacial acetic acid ( $\mathrm{vol} / \mathrm{vol})$ and cleared with lactoglycerol (equal parts lactic acid, glycerol, and water) as described before (4) to avoid displacement of ungerminated conidia and loosely attached germlings.

Microscopy. To stain fungal structures and facilitate microscopy, a drop of Aniline blue in lactoglycerol (0.1\%) was placed on a coverslip and a cleared leaf segment was lowered onto the coverslip so that its inoculated surface met the stain. The coverslip was then inverted onto a microscope slide smeared with lactoglycerol to complete the mount. This procedure minimizes displacement of loosely attached germlings or ungerminated conidia (15). Observations were made with a Leica DM LS phase contrast microscope (Leica Microsystems, Wetzlar, Germany) fitted with differential interference contrast and incident fluorescence attachments. To avoid possible interactive effects, outcomes of fungal attack were only recorded when a single fungal appressorium was in contact with a host cell.

Assessment of spore germination was carried out by examining 100 spores. To assess the developmental stages at which plant resistance interfered with fungal growth, 50 germlings with mature appressoria were examined on each replicate. Some epidermal cells survived attack and resisted penetration by producing an effective papilla beneath the appressorium of the fungus. Note was taken of whether germlings had penetrated successfully to form a visible haustorium within the subtending epidermal cell or a papilla had stopped the fungal development. In cases where cells were penetrated, the number of secondary hyphae and secondary appressoria developed by the germling was recorded. In some cases, penetrated epidermal cells died in response to attack following the hypersensitive response (HR). In these, cell cytoplasm was disorganized, and whole-cell autofluorescence visualized by incident fluorescence microscopy (blue exciter filter, max transmittance $400 \mathrm{~nm}$; dichroic mirror and barrier filter transmittance $>530 \mathrm{~nm}$ ) was evident throughout the cytoplasm and cell wall (6). Note was also taken of percentage of cells showing HR.

For all characteristics, percentage data were calculated for each leaf replicate. For statistical analysis, percentages were transformed to arcsine square roots (transformed value $=180 / \pi \times$ arcsine $[\sqrt{ }(\% / 100)])$ to normalize data and stabilize variances throughout the data range, and subjected to analysis of variance using GenStat 7th edition (VSN International, Ltd., UK), after which residual plots were inspected to confirm data conformed to normality.

\section{RESULTS}

The macroscopic assessment of the 277 M. truncatula accessions showed that most of them were highly susceptible to the isolate used in the present study. Thus, approximately $86 \%$ of accessions had more than $70 \%$ of the leaf area covered by mycelium or the leaf was so badly damaged that the whole leaf seemed wilted (Fig. 1). The other $10 \%$ of accessions were moderately susceptible with approximately 50 to $70 \%$ of leaf area covered by the fungus. Only $4 \%$ of the collection corresponding to 10 accessions was selected as resistant or moderately resistant with less than $40 \%$ of the leaf area covered by powdery mildew (Fig. 1).

Histological analysis of the 10 selected accessions revealed that resistance was due to different mechanisms and in some cases to a

TABLE 1. Microscopic assessment of Erysiphe pisi f. sp. medicaginis development and leaf epidermal cell responses of Medicago truncatula accessions ${ }^{\mathrm{a}}$

\begin{tabular}{|c|c|c|c|c|c|c|c|}
\hline \multirow[b]{2}{*}{ Accession } & \multirow[b]{2}{*}{$\%$ Germ } & \multicolumn{2}{|c|}{ Cells alive } & \multicolumn{3}{|c|}{ Cells dead } & \multirow{2}{*}{$\begin{array}{c}\%<1 \text { secondary appressorium } \\
\text { or secondary hypha }\end{array}$} \\
\hline & & $\% \mathrm{H}$ & $\% \mathrm{P}$ & $\% \mathrm{H}$ & $\% \mathrm{P}$ & $\%$ TDC & \\
\hline Parabinga & 65.45 & 77.50 & 13.00 & 6.50 & 2.00 & 8.50 & 24.05 \\
\hline PI190084 & 57.27 & $64.50 *$ & $34.00 * * *$ & $0.5^{*}$ & 1.00 & 1.50 & 33.71 \\
\hline PI190086 & 54.55 & 71.00 & 19.50 & 6.00 & 3.50 & 9.50 & $53.89 * *$ \\
\hline PI199257 & 58.18 & $53.00 * *$ & 15.00 & $30.00 * *$ & 2.00 & $32.00 * *$ & $50.17 *$ \\
\hline PI283661 & $50.91 *$ & 60.00 & 17.50 & 22.00 & 0.50 & 22.50 & 43.64 \\
\hline PI384647 & 60.00 & 81.00 & 10.00 & 8.00 & 1.00 & 9.00 & $48.84 *$ \\
\hline PI464816 & 54.55 & $31.50 * * *$ & $28.50 * *$ & $33.00 * *$ & $7.00 *$ & $40.00 * *$ & $58.26^{* *}$ \\
\hline PI564941 & $51.36^{*}$ & $57.50 *$ & $26.00 * *$ & 10.50 & 6.00 & 16.50 & $56.59 * *$ \\
\hline W65999 & $42.27 * * *$ & $37.00 * * *$ & $59.50 * * *$ & 3.00 & 0.50 & 3.50 & $71.18 * * *$ \\
\hline W66018 & $33.64 * * *$ & $34.50 * * *$ & 22.50 & $34.50 * *$ & $9.50 * *$ & $43.00 * * *$ & $87.14 * * *$ \\
\hline W66026 & $40.91 * * *$ & 60.00 & 20.50 & 12.00 & 7.50 & 19.50 & $58.55^{* *}$ \\
\hline
\end{tabular}

a Data were obtained at 48 hours after inoculation. Data corresponding to percentage of germination (Germ) were calculated from 100 conidia. The percentage of germlings that reached different developmental stages (passing from one stage to the next) (i.e., formed an appressorium but did not penetrate epidermal cell due to papilla formation $[\mathrm{P}]$, penetrated the cell and elicited cell death before or after haustorium [H] could be visible, or formed a colony but showing less than one secondary appressorium or secondary hypha) were assessed from 50 germinated spores in each of four replicate leaves. TDC = total dead cells. Analysis of variance was applied to transformed replicate data and was used to compare the studied accessions and the susceptible control Parabinga. *, **, and $* * *$ indicate significant differences at $P<0.05,0.01$, and 0.001 , respectively. The absence of asterisks indicates no significant difference. 
combination of these mechanisms. Some accessions (PI283661, PI564941, W65999, W66018, and W66026) showed a significantly lower percentage of spore germination than the susceptible control cv. Parabinga. From these, W66018 was the accession with the lowest percentage of germination, almost half the rate observed in the susceptible control (Table 1). In PI283661, reduced frequency of germination was the only resistance mechanism observed after detailed histological studies.

Some accessions (PI190084, PI190086, PI564941, and W65999) showed a high level of prepenetration/papilla resistance. That is, epidermal cells formed an effective papilla under the site of attempted attack preventing the penetration of the fungus. In these cases, the appressorial germ tube and the appressorium formed normally but no haustorium developed inside the cell (Fig. 2A). Frequently, though not invariably, papillae in such cells showed a localized yellow/green autofluorescence that was visualized by the incident fluorescence microscopy (Fig. 2A'). In accession PI190084, with a significantly higher papilla formation than Parabinga $(P<0.001)$, no other resistance mechanisms were observed and the prepenetration resistance by itself was responsible for the low level of symptoms macroscopically observed.

In several accessions (PI199257, PI384647, and W66018), most papillae were overcome by the fungal penetration peg that successfully reached the cell lumen. However, in these accessions, the HR stopped the fungal development. In these cases, cell cytoplasm was disorganized, and whole-cell autofluorescence was evident throughout the cytoplasm and cell wall (Fig. 2B and B'). In PI199257, the HR was the only resistance mechanism observed, with $32 \%$ of attacked cells dead (Table 1). This HR was not triggered immediately after cell penetration as in most of the cells (30\%) the haustorium was visible. Thus, the percentage of dead cells without visible haustoria was not significantly different from the susceptible control Parabinga (Table 1). In this accession, and probably due to this HR, the colonies remained small. Thus, the number of colonies with less than one secondary appressorium or hyphae was significantly lower than in the control (Table 1).

Accessions PI190086 and PI384647 also showed low level of visible symptoms after inoculation. These accessions were similar to the control with respect to percentage of germination, papilla formation, or percentage of living epidermal cells containing haustoria. Only colony size was markedly reduced, as expressed by proportion of colonies with less than one secondary appressorium or hyphae (Fig. 2C and D; Table 1). Because no other resistance mechanisms were observed in these accessions, the reduced colony size was attributed to posthaustorial resistance.

Interestingly, several accessions showed a combination of resistance mechanisms. Accession PI190086 showed a moderate level of prepenetration resistance $(28.5 \%)$ and also a significant high frequency of HR compared with the check cv. Parabinga. Furthermore, this HR was relatively fast since the percentage of dead cells with no visible haustoria was significantly higher than in Parabinga (Table 1). This accession had a small colony size probably due to this early HR. Accession W66018 had a reduced germination frequency. In addition, this accession also had a very high frequency of HR. Indeed, this accession had the highest frequency of HR. Moreover, it was very fast, showing the highest frequency of penetrated dead cells with no visible haustoria (Table 1). Both the high frequency of HR and rapidity of its development might be responsible for the highest frequency of small colonies observed with more than $85 \%$ of colonies developing less than one secondary appressorium or hyphae. This, added to the small germination frequency could explain why no macroscopic symptoms were observed in W66018.

Accessions PI564941, W65999, and W66026 showed a combination of low frequency of germination with posthaustorial resistance. Accession W65999 had the highest posthaustorial resistance as the small size of colonies could only be explained by resistance mechanisms acting after haustorium formation but not by HR as no dead cells were detected. In addition, PI564941 and W65999 also showed a high frequency of papilla formation. Indeed, W65999 had the highest level of prepenetration resistance (59.5\%, $P<0.001$; Table 1).

\section{DISCUSSION}

In the present study, resistance against powdery mildew was assessed in an M. truncatula collection. In previous work, Yaege and Stuteville (28) assessed different Medicago spp. for resistance to powdery mildew. In their work, they evaluated macroscopically nine M. truncatula accessions from which two (PI292436 and PI566892) were highly resistant. In our work, we assessed three of the accessions (PI292436, PI384648, and PI566886) studied by Yaege and Stuteville (28); however, all of them including PI292436 showed susceptibility in the macroscopic assay (approximately 100,90 , and $70 \%$ of leaf covered by mycelium, respectively) and hence they were not included for the microscopic assay. The contrasting results obtained with PI292436 suggest differences in the virulence of $E$. pisi isolates used in both studies. We cannot exclude a degree of specialization of isolates growing on alfalfa and on $M$. truncatula plants, but this needs further investigation.

In plants, resistance mechanisms may prevent powdery mildew infection at different developmental stages. It is known that within a very short time ( 0 to $3 \mathrm{~min}$ ) of conidial deposition on the leaf surface an extracellular material (ECM) is released, which may be involved in the rapid perception of the leaf surface $(13,15)$. It may be that ECM provides a means for the conidium to perceive the leaf surface and respond to it (15). This led Nielsen et al. (17) to consider the possibility that living conidia can take up external chemicals, possibly released by degradative enzymes associated with the ECM, prior to germination and that this uptake may be involved in the subsequent germ tube emergence. It is also well known than the physical structure and the chemical composition of the host surface, and especially of epicuticular leaf waxes, may influence germination and other prepenetration stages of powdery mildew $(3,9)$. Chemical compounds constitutively excreted to the leaf surface by some genotypes may also interfere with germination and initial developmental stages $(19,22)$. The differences in powdery mildew germination observed among accessions in the

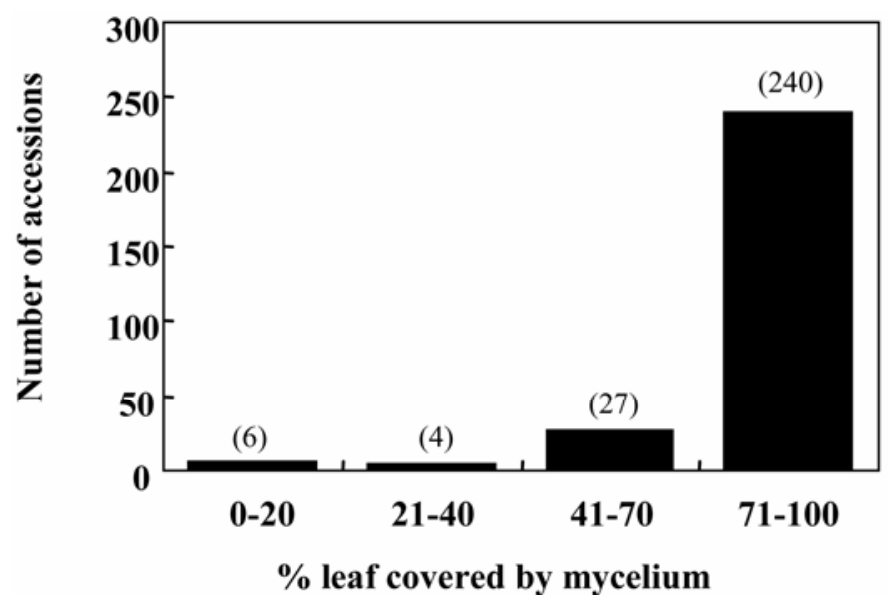

Fig. 1. Macroscopic assessment of Erysiphe pisi f. sp. medicaginis infection on Medicago truncatula leaves. The percentage of leaf covered by powdery mildew mycelia 8 days after inoculation was evaluated in 4-week-old $M$. truncatula plants. Figure represents the number of accessions with a determinate range of leaf covered by mycelium (exact number in brackets). Classification was made according to a discrete scale with the following percentages: $0,10,20,30,40,50,60,70,80,90$, and 100. Data are based on three plants and were calculated as the mean of the three leaves (one per plant) with the highest area covered by mycelium. Accessions from first and second range (0 to $40 \%$ ) were selected for microscopic assessment. 
present work support the hypothesis of mechanisms acting at this early developmental stage. However, further work is needed to unravel the nature of the specific mechanisms present in these genotypes.

The most efficient prepenetration resistance against powdery mildew is the formation of papillae (26). Papillae are cell wall appositions consisting in a callose matrix that contain various inorganic and organic constituents including proteins and phenolic compounds which are deposited on the inner surface of epidermal cell walls directly beneath appressoria (reviewed in literature citation 29). Thus, attacked cells that form an effective papilla survive (29). Here, we observed a reduced percentage of haustoria formation in the epidermal cells of several accessions, W65999 being the one with highest prepenetration resistance. Papilla effectiveness may relate to the rate of deposition, to quantitative or qualitative characteristics, or a combination of these factors. Phenolic compounds can be polymerized and cross-linked to form lignin or lignin-like polymers that strengthen cell walls and impede fungal penetration (5). Thus, strong autofluorescence has often been associated with penetration resistance although this fluorescence is more often observed in cereal than in legumepowdery mildew interactions, where often only the cell wall "halo" around papilla is visible (Fig. 2) (29). The fact that several accessions showed prepenetration resistance offers opportunities for breeding for this trait. This is of high importance since papilla resistance is non-race dependent and based on multiple and quantitative genes, and therefore, it is more difficult to be overcome by new races of pathogens than HR.

In addition to papilla resistance, cell death actively contributes to resistance in PI464816, PI199257, and W66018. Cell death following $\mathrm{HR}$ is one of the signs of incompatibility reaction between resistance $(R)$ and avirulence $(a v r)$ genes. Tosa and Shishiyama (26) and Johnson et al. (10), studying host and nonhost resistance responses, concluded that this form of resistance operates when the papilla barrier is overcome by the fungus. There- fore, accessions with high prepenetration resistance in addition to $\mathrm{HR}$, such as PI464816, might be highly useful as they ensure a more effective defense and might be more durable. In fact, it has been suggested that under field conditions HR may be relatively easily overcome by the evolving pathogen. Thus, coupling resistances affecting different phases of plant-pathogen interaction (e.g., papilla-based, penetration resistance together with death of attacked cells) and/or under genetically complex control, would present a series of barriers to pathogenesis. Such resistance should prove more durable than single gene controlled race-specific resistances that, although easily manipulated in plant breeding programs, have repeatedly proved ephemeral.

Interestingly, some accessions (PI190086, PI384647, and W66026) lacked in prepenetration resistance or HR but still showed very little macroscopic disease symptoms. Resistance in these genotypes was associated to mechanisms acting after haustorium formation. During establishment of a fungal biotrophic relationship (when a functional haustorium is formed), the pathogen is able to suppress, almost totally, the active host defenses although it is able to maintain functional membranes and energy generating for feeding from the host (14). That is, the pathogen is able to control host cell processes so that defensive responses are severely impaired while metabolic processes necessary to maintain fungal nutrition are preserved or enhanced. Resistance mechanisms acting after haustorium formation would lead to a restriction of nutrient flow to the pathogen, restricting their growth and delaying or impeding the sporulation. However, very little is known about this quantitative postpenetration resistance and a better understanding of haustorial function in susceptibility and resistance is needed.

The characterization of resistance operating in M. truncatula presented here is likely to be of high practical importance in legume breeding. First, the use of a plant genotype able to stop the pathogen at different developmental stages may prove more durable and difficult to be overcome than resistance based on a
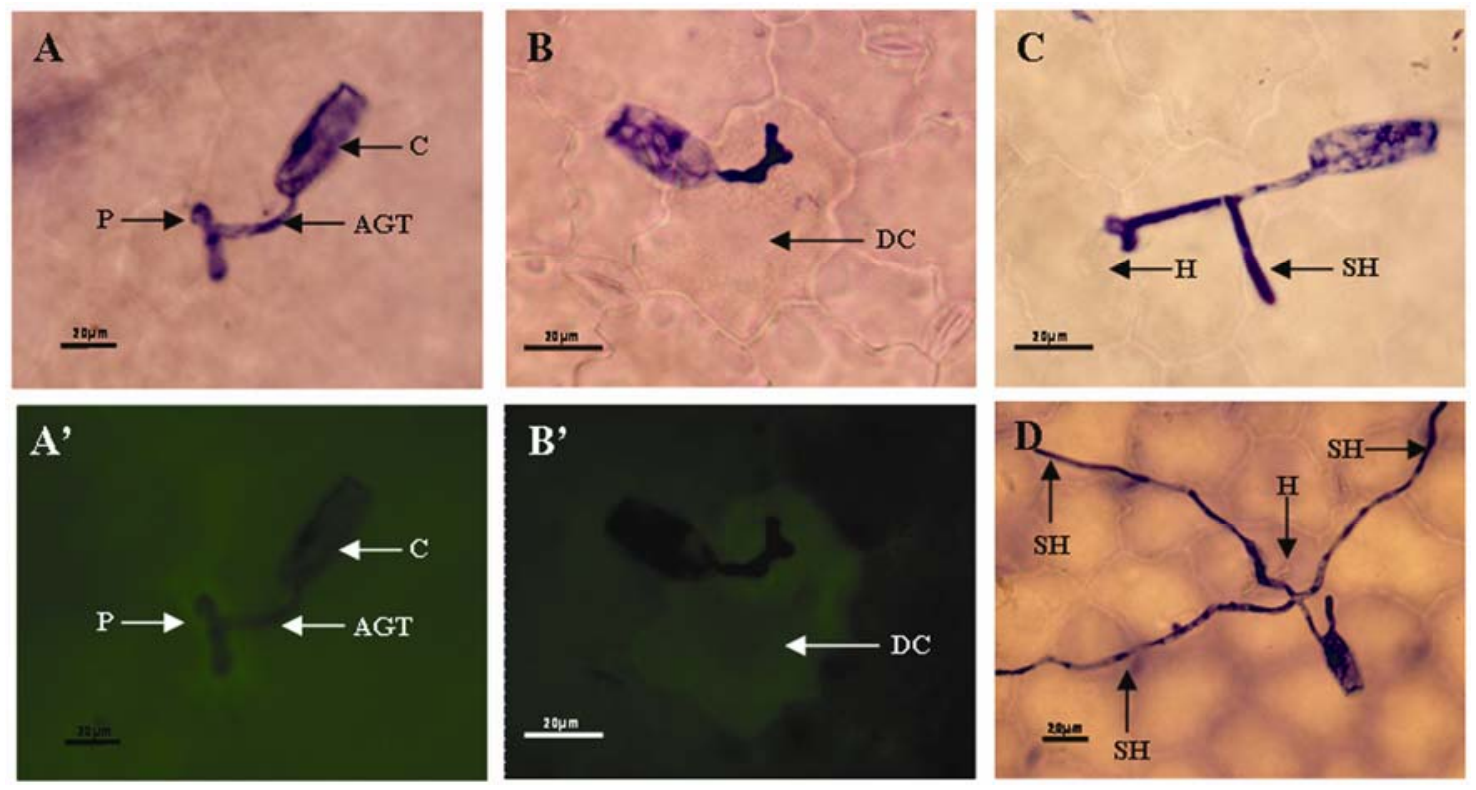

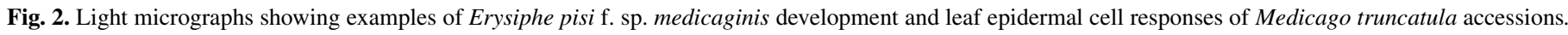

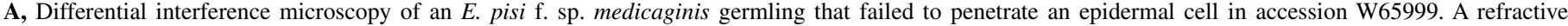

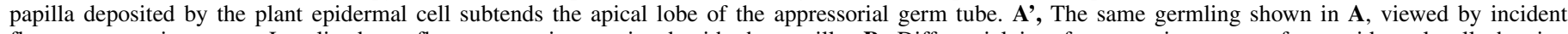

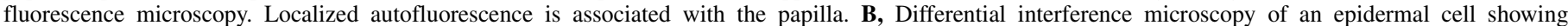

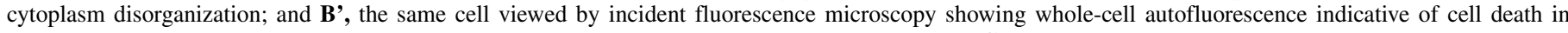

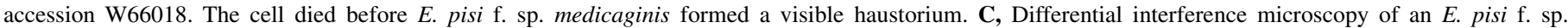

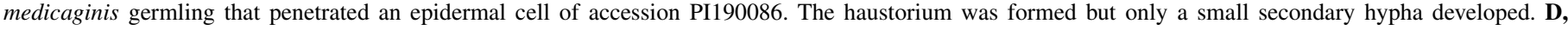

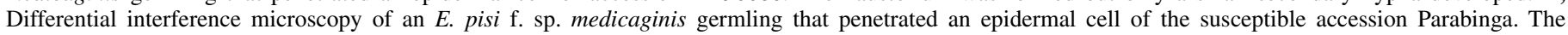

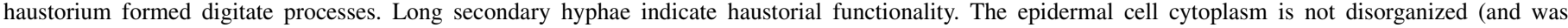

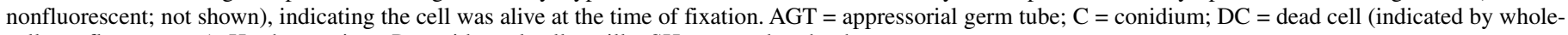
cell autofluorescence); $\mathrm{H}=$ haustorium; $\mathrm{P}=$ epidermal cell papilla; $\mathrm{SH}=$ secondary hyphae. 
single mechanism or mechanisms governed by a single gene, as occur in the HR. In the M. truncatula collection studied, we observed resistance mechanisms hampering fungal development at four different developmental stages: during germination, during penetration attempt, during first haustorium formation, and during colony growth. Interestingly, several genotypes showed resistance acting at several of these stages, which is of interest for future breeding programs. The understanding of the basic resistance processes may lead to improved cultivars with more durable resistance or to novel control strategies. In this sense, PI283661, PI190084, PI199257 and PI190086, or PI384647 would be very useful for studies on inhibition of germination, papilla formation, $\mathrm{HR}$, and postpenetration non-HR resistance, respectively. In this sense, our group is currently carrying out molecular studies on the basis of papilla formation, taking advantage of the ample molecular data available for M. truncatula. Third, understanding the resistance mechanisms acting in the genotypes may be useful to avoid adverse physiological consequences of resistance mechanisms. For instance, HR has been associated with a disruption of stomatal functions leading to a lack of the control of carbohydrate metabolism and the ability of plants to withstand drought (21), which implies an energetic cost (24). Expression of papilla-based resistance had only a temporary effect on stomatal function (21). This would be an additional advantage for the use of papillabased resistant genotypes such as PI190084, PI464816, and W65999 in plant breeding.

\section{ACKNOWLEDGMENTS}

This work was supported by a Marie Curie European Reintegration Grant of the European Union (MERG-CT-2004-013083) and Spanish CICYT project AGL2005-01781.

\section{LITERATURE CITED}

1. Anderson, J. P., Thatcher, L. F., and Singh, K. B. 2005. Plant defense responses: Conservation between models and crops. Funct. Plant Biol. 32:21-34.

2. Barker, D., Bianchi, S., Blondon, F., Dattee, Y., Duc, G., Flament, P., Gallusci, P., Genier, P., Guy, P., and Muel, X. 1990. Medicago truncatula, a model plant for studying the molecular genetics of the Rhizobium legume symbiosis. Plant Mol. Biol. 8:40-49.

3. Carver, T. L. W., and Ingerson, S. M. 1987. Responses of Erysiphe graminis germlings to contact with artificial and host surfaces. Physiol. Mol. Plant Pathol. 30:359-372.

4. Carver, T. L. W., Zeyen, R. J., Bushnell, W. R., and Robbins, M. P. 1994. Inhibition of phenylalanine ammonia-lyase and cinnamyl alcoholdehydrogenase increases quantitative susceptibility of barley to powdery mildew (Erysiphe graminis DC). Physiol. Mol. Plant Pathol. 44:261-272.

5. Cassab, G. I. 1998. Plant cell wall proteins. Annu. Rev. Plant Physiol. Plant Mol. Biol. 49:281-309.

6. Clark, T. A., Zeyen, R. J., Carver, T. L. W., Smith, A. G., and Bushnell, W. R. 1995. Epidermal-cell cytoplasmic events and response gene transcript accumulation during Erysiphe graminis attack in isogenic barley lines differing at the MLO locus. Physiol. Mol. Plant. Pathol. 46:1-16.

7. Cook, D. R. 1999. Medicago truncatula - A model in the making! Comment. Curr. Opin. Plant Biol. 2:301-304.

8. Dita, M. A., Rispail, N., Prats, E., Rubiales, D., and Singh, K. B. 2006. Biotechnology approaches to overcome biotic and abiotic stress constraints in legumes. Euphytica 147:1-24.

9. Gniwotta, F., Vogg, G., Gartmann, V., Carver, T. L. W., Riederer, M., and
Jetter, R. 2005. What do microbes encounter at the plant surface? Chemical composition of pea leaf cuticular waxes. Plant Physiol. 139:519-530.

10. Johnson, L. E. B., Bushnell, W. R., and Zeyen, R. J. 1982. Defense patterns in non-host higher-plant species against 2 powdery mildew fungi. 1. Monocotyledonous species. Can. J. Bot. 60:1068-1083.

11. Koga, H., Mayama, S., and Shishiyama, J. 1980. Correlation between the deposition of fluorescent compounds in papillae and resistance in barley against Erysiphe graminis hordei. Can. J. Bot. 58:536-541.

12. Kruger, W. M., Carver, T. L. W., and Zeyen, R. J. 2002. Effects of inhibiting phenolic biosynthesis on penetration resistance of barley isolines containing seven powdery mildew resistance genes or alleles. Physiol. Mol. Plant Pathol. 61:41-51.

13. Kunoh, H., Nicholson, R. L., Yosioka, H., Yamaoka, N., and Kobayashi, I. 1990. Preparation of the infection court by Erysiphe graminis degradation of the host cuticle. Physiol. Mol. Plant Pathol. 36:397-407.

14. Leckie, C. P., Callow, J. A., and Green, J. R. 1995. Reorganization of the endoplasmic reticulum in pea leaf epidermal cells infected by the powdery mildew fungus Erysiphe pisi. New Phytol. 131:211-221.

15. Lyngkjær, M. F., and Carver, T. L. W. 1999. Induced accessibility and inaccessibility to Blumeria graminis f. sp. hordei in barley epidermal cells attacked by a compatible isolate. Physiol. Mol. Plant Pathol. 55:151-162.

16. Michalk, D. L., and Beale, J. A. 1976. Evaluation of barrel medic (Medicago truncatula) as an introduced pasture legume for marginal cropping areas of southeastern Australia. J. Range Manage. 29:328-333.

17. Nielsen, K. A., Nicholson, R. L., Carver, T. L. W., Kunoh, H., and Oliver, R. P. 2000. First touch: An immediate response to surface recognition in conidia of Blumeria graminis. Physiol. Mol. Plant Pathol. 56:63-70.

18. Niks, R. E., and Rubiales, D. 2002. Potentially durable resistance mechanisms in plants to specialized fungal pathogens. Euphytica 124:201-216.

19. Pasechnik, T. D., Lapikova, V. P., and Averyanov, A. A. 1997. Inhibition of pre-penetration development of blast fungus during the infection of resistant rice cultivars. Eur. J. Plant Pathol. 103:747-750.

20. Poulter, R., Harvey, L., and Burritt, D. J. 2003. Qualitative resistance to powdery mildew in hybrid sweet peas. Euphytica 133:349-358.

21. Prats, E., Gay, A. P., Mur, L. A. J., Thomas, B. J., and Carver, T. L. W. 2006. Stomatal lock-open, a consequence of epidermal cell death, follows transient suppression of stomatal opening in barley attacked by Blumeria graminis. J. Exp. Bot. 57:2211-2226.

22. Prats, E., Llamas, M. J., Jorrín, J., and Rubiales, D. 2007. Constitutive coumarin accumulation on sunflower leaf surface prevents rust germ tube growth and appressorium differentiation. Crop Sci. 47:1119-1124.

23. Sillero, J. C., Fondevilla, S., Davidson, J., Patto, M. C. V., Warkentin, T. D., Thomas, J., and Rubiales, D. 2006. Screening techniques and sources of resistance to rusts and mildews in grain legumes. Euphytica 147:255272.

24. Smedegaard-Petersen, V., and Stølen, O. 1981. Effect of energy requiring defense reactions on yield and grain quality in a powdery mildew resistant barley cultivar. Phytopathology 71:396-399.

25. Smith, P. H., Foster, E. M., Boyd, L. A., and Brown, J. K. M. 1996. The early development of Erysiphe pisi on Pisum sativum L. Plant Pathol. 45:302-309.

26. Tosa, Y., and Shishiyama, J. 1984. Defense reactions of barley cultivars to an inappropriate forma specialis of the powdery mildew fungus of gramineous plants. Can. J. Bot. 62:2114-2117.

27. Vanacker, H., Carver, T. L. W., and Foyer, C. H. 2000. Early $\mathrm{H}_{2} \mathrm{O}_{2}$ accumulation in mesophyll cells leads to induction of glutathione during the hyper-sensitive response in the barley-powdery mildew interaction. Plant Physiol. 123:1289-1300.

28. Yaege, J. R., and Stuteville, D. L. 2002. Reactions of accessions in the annual Medicago core germ plasm collection to Erysiphe pisi. Plant Dis. 86:312-315.

29. Zeyen, R. J., Carver, T. L. W., and Lyngkjaer, M. F. 2002. Epidermal cell papillae. Pages 107-125 in: Powdery Mildews: A Comprehensive Treatise. R. R. Belanger, W. R. Bushnell, A. J. Dik, and T. L. W. Carver, eds. American Phytopathological Society, St. Paul, MN. 